\title{
Isolation and identification of a yeast strain capable of degrading four and five ring aromatic hydrocarbons
}

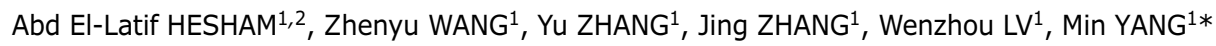 \\ ${ }^{1}$ State Key Laboratory of Environmental Aquatic Chemistry, Research Center for Eco-Environmental Sciences, Chinese Academy \\ of Sciences, P.O. Box 2871, Beijing 100085, P.R. China; ${ }^{2}$ Genetic Department, Faculty of Agriculture, Assiut University, Assiut, Egypt
}

Received 15 November 2005 / Accepted 7 April 2006

\begin{abstract}
A yeast strain AEH was isolated from oil contaminated soil and identified by analysis of $18 \mathrm{~S}$ and $26 \mathrm{~S}$ ribosomal DNA sequences as Pichia anomala. Strain AEH was capable of degrading naphthalene, phenanthrene and chrysene, singly, and benzo(a)pyrene in combination. The yeast degraded $5.36 \mathrm{mg}$ naphthalene $\mathrm{I}^{-1}$ within 2 days, and $5.04 \mathrm{mg}$ phenanthrene $\mathrm{I}^{-1}$ and $1.54 \mathrm{mg}$ chrysene $1^{-1}$ within 10 days. When a mixture of the four polycyclic aromatic hydrocarbons (PAHs) was treated at a concentration between $2.98 \mathrm{mg} \mathrm{l}^{-1}$ and $6.89 \mathrm{mg} \mathrm{l}^{-1}$, degradation rates were delayed for naphthalene and phenanthrene (3.79 $\mathrm{mg} \mathrm{l}^{-1}$ and, $4.20 \mathrm{mg} \mathrm{l}^{-1}$ within 10 days, respectively), but enhanced for chrysene and benzo(a)pyrene $\left(3.37 \mathrm{mg} \mathrm{l}^{-1}\right.$ and, $1.91 \mathrm{mg} \mathrm{l}^{-1}$ within 10 days, respectively). In a binary system, all of the other 3 PAHs could be utilized as the carbon source for the cometabolic degradation of benzo(a)pyrene with naphthalene as the best one.
\end{abstract}

Key words: biodegradation; chrysene; benzo(a)pyrene; isolation; yeast; ribosomal DNA.

\section{INTRODUCTION}

The universal presence of polycyclic aromatic hydrocarbons (PAHs) in the environment has attracted wide attentions of environmental researchers (Juhasz and Naidu, 2000). PAHs are widespread in the environment, being found in air, water and soil. They are formed naturally during the incomplete combustion of organic matter or by many anthropogenic activities, such as the petrochemical industry and oil refining. PAHs generally occur as complex mixtures and not as a single compound in environmental samples. Some PAHs are highly toxic, mutagenic and carcinogenic; exposure to PAHs represents a public health risk and raises environmental concerns (Mastrangelo et al., 1996; Goldman et al., 2001). Many researchers have been focusing on the biodegradation of PAHs, and a large number of bacteria capable of degrading PAHs have been isolated. Although yeasts are tolerant to changes in the environmental conditions (Cerniglia and Crow, 1981; Ooi et al., 2003), biodegradation of PAHs by yeasts, especially for high molecular weight PAHs, has been minimal (Cerniglia and Crow, 1981; Hofmann, 1986; McGillivray and Sharis, 1993; Romero et al., 1998; Zinjarde et al., 2002; Ren et al., 2004).

Many studies have been performed on the bacterial and fungal biotransformation and biodegradation of individual PAHs and related compounds. However, relatively little is known of the biodegradation of PAHs when they are pres-

\footnotetext{
* Corresponding author. Fax: +86-10-62923475;

E-mail: yangmin@ rcees.ac.cn
}

ent in mixtures. In this study, isolation of yeast strains with the ability to degrade higher molecular weight PAHs was conducted by enrichment of soil samples in phenanthrene-bearing cultures. The ability of one yeast of screened isolates, strain AEH to degrade benzo(a)pyrene in sole, binary and mixed PAH systems was evaluated.

\section{MATERIALS AND METHODS}

Chemicals. Naphthalene, phenanthrene, chrysene and benzo(a)pyrene were acquired with the highest purity (Acros Organic Co.).

Enrichment and isolation. Oily soil samples were taken from Jidong Oilfield in Hebei Province, China. About $1 \mathrm{~g}$ soil was suspended in $10 \mathrm{ml}$ sterile water and added to a mineral basal salts (MBS containing, per litre of distilled water, $1000 \mathrm{mg}\left(\mathrm{NH}_{4}\right)_{2} \mathrm{SO}_{4}, 800 \mathrm{mg} \mathrm{K} \mathrm{HPO}_{4}, 200 \mathrm{mg} \mathrm{KH} \mathrm{PO}_{4}, 200$ $\mathrm{mg} \mathrm{MgSO} 4 \cdot 7 \mathrm{H}_{2} \mathrm{O}, 100 \mathrm{mg} \mathrm{CaCl} 2 \cdot 2 \mathrm{H}_{2} \mathrm{O}, 5 \mathrm{mg} \mathrm{FeSO}{ }_{4} \cdot 7 \mathrm{H}_{2} \mathrm{O}, \mathrm{pH}$ 5-6 and $1 \mathrm{ml}$ of vitamin solution sterilized by filtration) medium supplemented with $0.2 \%$ phenanthrene at $27^{\circ} \mathrm{C}$ at 150 rpm for 10 days. When growth was visible, enrichment was continued by serially sub-culturing several times in the same medium, using a $10 \%$ inoculum from the previous culture. Yeast strains were isolated from MBS agar plates coated with phenanthrene as the sole carbon source (Romero et al., 1998).

DNA extraction. The DNA extraction was performed according to procedures described by Harju et al. (2004). Briefly, a single colony was inoculated into YPD media ( $1 \%$ yeast 
extract, $2 \%$ peptone, $2 \%$ dextrose), and grown in a shaking water bath at $30^{\circ} \mathrm{C}$ for approximately $20 \mathrm{~h}$. Cells from $1.5 \mathrm{ml}$ of the overnight cultures were pelleted in a microcentrifuge tube and washed twice by distilled water. The cell pellets were resuspended in $200 \mu$ of lysis buffer ( $2 \%$ Triton X-100,1\% SDS, 100 mM NaCl, 10 mM Tris-HCl pH 8.0, $1 \mathrm{mM}$ EDTA pH 8.0). The tubes were placed in a $-80^{\circ} \mathrm{C}$ freezer for $5 \mathrm{~min}$, and then immersed in a $95^{\circ} \mathrm{C}$ water-bath for $3 \mathrm{~min}$ to thaw quickly. This step was repeated once, and the tubes were vortexed vigorously for $30 \mathrm{~s}$. Phenol-chloroform $(1: 1,200 \mu \mathrm{l})$ was added and the tubes were vortexed for 2 min and then centrifuged $3 \mathrm{~min}$ at room temperature at $20000 \times g$. The aqueous layer was transferred to a tube containing $400 \mu \mathrm{l}$ of ice-cold $100 \%$ ethanol for $5 \mathrm{~min}$ at room temperature and then centrifuged $5 \mathrm{~min}$ at room temperature at $20000 \times g$. Supernatants were discarded and DNA pellets were washed with $0.5 \mathrm{ml}$ of $70 \%$ ethanol followed by vacuum drying for $20 \mathrm{~min}$ at room temperature and then DNA was resuspended in $20 \mu \mathrm{l}$ TE buffer.

Identification of PAHs utilizing yeast by D1/D2 rDNA and 185 rDNA sequences. The identification was performed by sequencing $18 \mathrm{~S}$ and $26 \mathrm{~S}$ ribosomal DNA. DNA was isolated and fragments containing the D1/D2 region of about 600-650 bp at the $5^{\prime}$ end of the 26S rDNA were amplified using primers: NL-1 (5'-GCA TAT CAA TAA GCG GAG GAA AAG-3') and NL-4 (5'-GGT CCG TGT TTC AAG ACG G-3'). The $18 \mathrm{~S}$ rDNA was amplified using primers: NS1 (5'-GTAGTCATATGCTTGTCTC-3') and NS2 (5'-GGCTGCTGGCACCA GACTTGC-3') (Kurtzman and Robnett 1998; 2003). All polymerase chain reaction (PCR) reactions were performed in a final volume of $50 \mu$ l containing $10 \mathrm{mM}$ Tris- $\mathrm{HCl}, 50 \mathrm{mM} \mathrm{KCl}$, $1.5 \mathrm{mM} \mathrm{MgCl}_{2}$, each dNTPs at a concentration of $0.2 \mathrm{mM}$, 1.25 IU of Taq polymerase (Takara, Dalian, China), each primer at a concentration of $0.2 \mathrm{mM}$ and $1 \mu \mathrm{l}$ of DNA template. The amplification was carried out by PCR under the following conditions: initial denaturation at $95^{\circ} \mathrm{C}$ for $5 \mathrm{~min}$, followed by 36 cycles at $94{ }^{\circ} \mathrm{C}$ for $2 \mathrm{~min}, 52{ }^{\circ} \mathrm{C}$ for $1 \mathrm{~min}$, $72{ }^{\circ} \mathrm{C}$ for $2 \mathrm{~min}$; final extension at $72^{\circ} \mathrm{C}$ for $7 \mathrm{~min}$ and holding at $4^{\circ} \mathrm{C}$. The amplified products were then purified and sequenced (Shanghai GeneCor Biotechnologies Co., Ltd). The obtained sequence data were compared with those of all known yeast species available at the GenBank database.

Degradation of PAHs in liquid cultures. For each $\mathrm{PAH}$, $100 \mathrm{mg}$ was dissolved in $10 \mathrm{ml}$ acetone, added to $50 \mathrm{~g}$ Tween 80 in $50 \mathrm{ml}$ distilled water, ultrasonicated, and the suspension was diluted with water to make $200 \mathrm{ml}$ (Andres et al., 1999).

In all experiments (three replicates), $5 \mathrm{ml}$ batch cultures were grown in $40 \mathrm{ml}$ sample tubes with screw caps and Teflon-lined septa. The isolate was pre-cultivated at 150 rpm at $27^{\circ} \mathrm{C}$ in the following basal medium (BM): $\mathrm{KH}_{2} \mathrm{PO}_{4}$ $1 \mathrm{~g},\left(\mathrm{NH}_{4}\right)_{2} \mathrm{SO}_{4} 0.5 \mathrm{~g}, \mathrm{MgSO}_{4} \cdot 7 \mathrm{H}_{2} \mathrm{O} 0.5 \mathrm{~g}$, yeast extract 0.5 $\mathrm{g}$, distilled water $1000 \mathrm{ml}$, pH 5-6, supplemented with $10 \mathrm{~g}$ glucose (Yang et al., 2003). Cells were harvested by centrifugation, washed twice with sterile BM and inoculated into the modified BM supplemented with sole or mixtures of PAHs as the carbon source. The inoculum was controlled to approx. $2.4 \times 10^{8}$ cells $\mathrm{ml}^{-1}$. In addition, two controls were added to the experimental design and included a no-cell control and a dead-cell control (autoclaved). Cultures were grown in the dark with tumble-shaking at $150 \mathrm{rpm}$ and $27^{\circ} \mathrm{C}$ (McNally et al., 1999).
All results of biodegradation were obtained in reference to controls. The total biodegradation rate (\%B) was determined by the equation $\% \mathrm{~B}=100 \cdot(\mathrm{W} 1-\mathrm{WC}) / \mathrm{W} 1$, in which $\mathrm{W} 1$ is the mass of the residue in the control and $W C$ is the mass of the fraction in the treatment.

Analysis. Hexane $(5 \mathrm{ml}$ ) was added to each culture, shaken horizontally for $2 \mathrm{~h}$ at $150 \mathrm{rpm}$ and approx. $2 \mathrm{ml}$ of the hexane layer was placed in an autosampler vial, crimpsealed with a Teflon-lined cap, and then stored at $-20^{\circ} \mathrm{C}$ until analysis (Leblond et al., 2001). The concentrations of PAHs in the extracts were determined by an Agilent 6890 gas chromatography equipped with a 5973 mass selective detector under the selected ion monitoring mode. An HP-5 silica fused capillary column ( $60 \mathrm{~m} \times 0.25 \mathrm{~mm}$ inner diameter $\times$ $0.25 \mu \mathrm{m}$ film thickness) was used with helium as the carrier gas at a constant flow rate of $1 \mathrm{ml} \mathrm{min}^{-1}$. The GC oven temperature was programmed from $50^{\circ} \mathrm{C}(2 \mathrm{~min})$ to $200^{\circ} \mathrm{C}$ ( 2 min) at $10^{\circ} \mathrm{C} \mathrm{min}-1$, then to $290^{\circ} \mathrm{C}$ at $20^{\circ} \mathrm{C} \mathrm{min}^{-1}$ and held for $8 \mathrm{~min}$. The injector and detector temperatures were $280^{\circ} \mathrm{C}$ and $290^{\circ} \mathrm{C}$, respectively. Mass spectra were acquired at the electron ionisation (EI) mode with an electron multiplier voltage of $1906 \mathrm{eV}$. Quantization was performed using the five-point calibration curve for individual components. The detection limit for all PAHs was $0.001-0.01 \mathrm{mg} \mathrm{l}^{-1}$.

Nucleotide sequence accession numbers. The partial $18 \mathrm{~S}$ and $26 \mathrm{~S}$ ribosomal DNA sequences of strain AEH reported in this paper has been deposited in the DDBJ, EMBL, and GenBank databases under accession numbers (DQ432636 and DQ432635_respectively).

\section{RESULTS AND DISCUSSION}

\section{Enrichment and isolation of PAHs utilizing yeast}

Fifteen yeast strains were isolated from phenanthrene coated agar plates, and all of them were able to grow on agar plates coated with phenanthrene, chrysene, or benzo(a)pyrene as the sole carbon source. One isolate, which rapidly grew on agar plates coated with benzo(a)pyrene (the first colony appeared on the fifth day), was selected for further study. Some studies demonstrated that the microorganisms isolated on naphthalene as the sole carbon source were unable to grow on anthrance, phenanthrene, fluranthene, or pyrene, whereas microorganisms isolated on any of the other four compounds were able to grow on at least one of the other substrates (Aitken et al., 1998). Our previous study demonstrated that the yeast Pichia anomala, which was isolated on naphthalene as the sole carbon source, could grow on agar plates coated with phenanthrene or dibenzothiophene but failed to grow on those coated with chrysene (Pan et al., 2004). So, by selecting phenanthrene as the sole carbon source, a more powerful strain that could grow on chrysene and benzo(a)pyrene was acquired.

\section{Identification of PAHs utilizing yeast}

The BLAST search result through GenBank indicated that the D1/D2 (26S) rDNA and 18S rDNA sequences of the selected strain had high similarity with Pichia anomala. The sequencing results of $18 \mathrm{~S}$ rDNA and the D1/D2 of the large subunit 26S rDNA were submitted to the GenBank database and the accession numbers are as indicated (DQ432636 and DQ432635, respectively). 


\section{Degradation of PAHs in liquid cultures}

Degradation of sole PAHs by strain AEH in liquid cultures is shown in figure 1 . This yeast completely degraded $5.36 \mathrm{mg}$ naphthalene $\mathrm{I}^{-1}$ within 2 days, and $5.04 \mathrm{mg}$ phenanthrene $\mathrm{I}^{-}$ ${ }^{1}$ within 10 days, respectively, and $1.54 \mathrm{mg}$ chrysene $1^{-1}$ was degraded during 10 days. The compounds with a lower molecular weight tended to degrade at faster rates than those with a higher molecular weight (Bossert and Bartha, 1986). Pichia anomala isolated in our previous study could only degrade chrysene when naphthalene coexisted. The strain AEH, however, could utilize chrysene directly as the carbon source. However, the isolate was not effective for the decomposition of benzo(a)pyrene although it could grow on the benzo(a)pyrene coated agar plates.

The results in figure 2 show that when the 4 PAHs were simultaneously present, degradation rates were delayed for naphthalene and phenanthrene $(55.7 \%$ and $60.9 \%$ respectively), but enhanced for chrysene and benzo(a)pyrene whereas: $75.9 \%$ chrysene and $63.8 \%$ benzo(a)pyrene were removed at the end of the experiment (10 days). This is the first report about the degradation of benzo(a)pyrene by yeast. It is clear that chrysene and benzo(a)pyrene in the

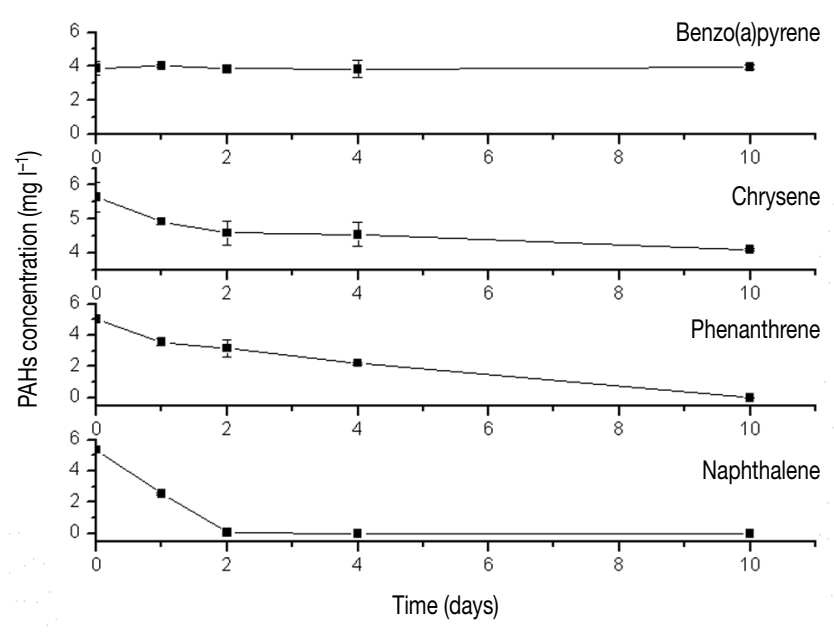

FIG. 1 - Degradation of sole PAHs by yeast strain AEH .The initial concentration of each PAH was: naphthalene, 5.36 $\mathrm{mg} \mathrm{l}^{-1}$; phenanthrene, $5.04 \mathrm{mg} \mathrm{I}^{-1}$; chrysene, $5.63 \mathrm{mg}$ $\mathrm{I}^{-1}$; benzo(a)pyrene, $3.87 \mathrm{mg} \mathrm{l}^{-1}$. Each point represents mean \pm S.E. of triplication.

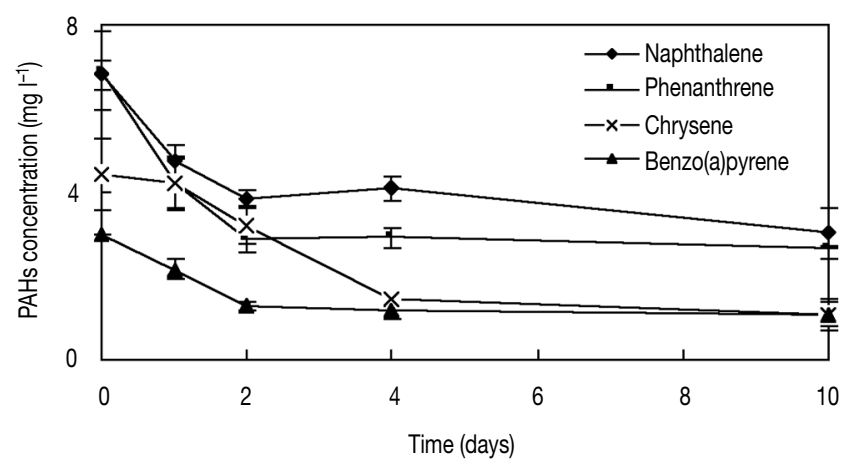

FIG. 2 - Degradation of PAHs by yeast strain AEH in mixture solutions. The initial concentration of each PAH was: naphthalene, $6.80 \mathrm{mg} \mathrm{l}^{-1}$; phenanthrene, $6.89 \mathrm{mg} \mathrm{I}^{-1}$; chrysene, $4.44 \mathrm{mg} \mathrm{l}^{-1}$; benzo(a)pyrene, $2.98 \mathrm{mg} \mathrm{I}^{-1}$. Each point represents mean \pm S.E. of triplication. mixture of the 4 PAHs were removed through the cometabolism mechanism, indicating that chrysene could be decomposed by the yeast through two mechanisms: direct degradation or cometabolism. When lower molecular weight PAHs are present, the yeast seems prefer to select the cometabolism mechanism. On the other hand, the delayed degradation rates of naphthalene and phenanthrene indicated possible metabolic competition between the high molecular weight group (chrysene and benzo(a)pyrene) and the low group (naphthalene and phenanthrene). Similar phenomena have been observed by many researchers on bacteria. $A$ competitive inhibition was able to represent the kinetics of degradation of PAHs from the creosote contaminated soil (Lotfabad and Gray, 2002). Yuan et al. (2000), found that degradation rates by mixed culture bacteria were delayed for phenanthrene, pyrene, and acenaphthene, but enhanced for anthracene and fluorine when all of the 5 PAHs were simultaneously present. Our previous study also demonstrates that Pichia anomala degraded phenanthrene in a mixture of $4 \mathrm{PAHs}$ at a rate slower than that in sole solution because of the competitive inhibition between dibenzothiophene and phenanthrene (Pan et al., 2004).

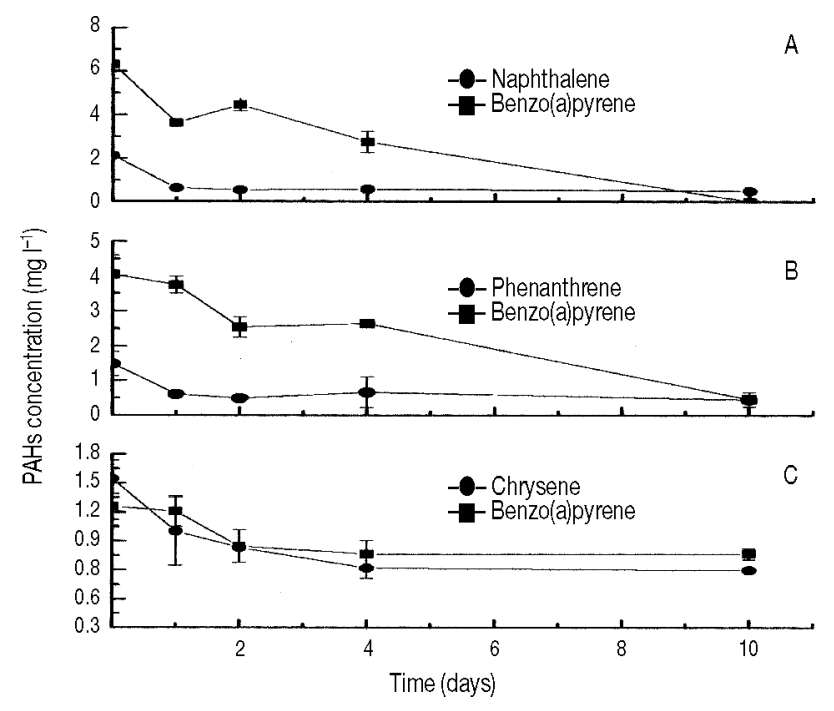

FIG. 3 - Degradation of PAHs by yeast strain AEH in binary solutions. The initial concentration of each PAH was: (A) naphthalene, $6.34 \mathrm{mg} \mathrm{l}^{-1}$; benzo(a)pyrene, $2.12 \mathrm{mg} \mathrm{l}^{-1}$. (B) phenanthrene, $4.05 \mathrm{mg} \mathrm{l}^{-1}$; benzo(a)pyrene, 1.48 $\mathrm{mg} \mathrm{I}^{-1}$. (C) chrysene, $1.26 \mathrm{mg} \mathrm{I}^{-1}$; benzo(a)pyrene, $1.55 \mathrm{mg} \mathrm{l}^{-1}$. Each point represents mean \pm S.E. of triplication.

TABLE 1 - Properties of polycyclic aromatic hydrocarbons used in this study

\begin{tabular}{ll} 
PAH & $\begin{array}{c}\text { Aqueous solubility } \\
\text { at } 25^{\circ} \mathrm{C}\left(\mathrm{mg} \mathrm{l}^{-1}\right)\end{array}$ \\
Chrysene & 31.7 \\
Benzo(a)pyrene & 0.002 \\
\hline
\end{tabular}


Since a high ratio of benzo(a)pyrene removal was recorded in the PAHs mixture, an attempt was made to test the effect of other aromatic ring structure on benzo(a)pyrene degradation. Figure $3(A, B$ and $C$ ) present data on biodegradation of benzo(a)pyrene in a binary system with each one of the other PAHs (naphthalene, phenanthrene and chrysene). It is clear that benzo(a)pyrene could be degraded in each binary system, further proving that benzo(a)pyrene could be decomposed with a cometabolism, and all of the other 3 PAHs could be utilized as the carbon sources. The degradation ratio at the end of 10 days was $76.8 \%, 65.5 \%$ and $61.5 \%$ with naphthalene, phenanthrene and chrysene, respectively. It is also interesting to note that naphthalene was promoting the degradation of benzo(a)pyrene more than other components. It is possible that the high aqueous solubility of naphthalene (see Table 1) was inducing high amount of enzymes required for degradation of benzo(a)pyrene. The competition inhibition between low and high molecular weigh PAHs may also explain why degradation of benzo(a)pyrene was lower in mixture than in binary PAHs.

\section{CONCLUSION}

The strain $\mathrm{AEH}$ which could utilize naphthalene, phenanthrene and chrysene as the sole carbon source, and degrade all of the 4 PAHs when the 3 PAHs coexisted with benzo(a)pyrene was acquired. The yeast preferred cometabolic degradation in the solution containing the binary or mixture of PAHs. It is clear that benzo(a)pyrene could be decomposed by the yeast only through cometabolism while chrysene through two mechanisms: direct degradation or cometabolism. Naphthalene promoted the degradation of benzo(a)pyrene more than the other two PAHs. The role of yeast in PAH bioremediation in the environment is an interesting topic for the future studies.

\section{Acknowledgments}

This study was supported by the National Natural Science Foundation of China (No. 20337020), the National Basic Research Program of China (No. 2003CB415006) and the National Natural Science Foundation of China (No. 50525824).

\section{REFERENCES}

Aitken M.D., Stringfellow T.W., Nagel D.R., Kazunga C., Chen S.H. (1998). Characteristics of phenanthrene-degrading bacteria isolated from soils contaminated with polycyclic aromatic hydrocarbons. Can. J. Microbiol., 44: 743-752.

Andres S., Andrzej M., Christian J., Aloys H. (1999). Degradation of fluorene, anthracene, phenanthrene, fluoranthene, and pyrene lacks connection to the production of extracellular enzymes by Pleurotus ostreatus and Bjerkandera adusta. Int. Biodeterior. Biodegrad., 43: 93-100.

Bossert I.D., Bartha R. (1986). Structure biodegradability relationships of polycyclic aromatic hydrocarbons in soil. Bull. Environ. Contam. Toxicol., 37:490-495.
Cerniglia C.E., Crow S.A. (1981). Metabolism of aromatic hydrocarbons by yeasts. Arch. Microbiol., 129: 9-13.

Goldman R., Enewold L., Pellizzari E., Beach B.J., Bowman D.E., Krishnan S.S., Shields G.P. (2001). Smoking increase carcinogenic polycyclic aromatic hydrocarbons in human lung tissue. Cancer Res., 61: 6367-6371.

Harju S., Fedosyuk H., Peterson K.R. (2004). Rapid isolation of yeast genomic DNA: Bust n' Grab. BMC Biotechnol., 4: 8.

Hofmann K.H. (1986). Oxidation of naphthalene by Saccharomyces cerevisiae and Candida utilis. J. Basic Microbiol., 26: 109-111.

Juhasz A.L., Naidu R. (2000). Bioremediation of high molecular weight polycyclic aromatic hydrocarbons: a review of the microbial degradation of benzo[a]pyrene. Int. Biodeterior. Biodegrad., 45: 57-88.

Kurtzman C.P., Robnett C.J. (1998). Identification and phylogeny of ascomycetous yeasts from analysis of nuclear large subunit (26S) ribosomal DNA partial sequences. Antoine van Leeuweenhoek, 73: 331-371.

Kurtzman C.P., Robnett C.J. (2003). Phylogenetic relationships among yeasts of the Saccharomyces complex determined from multigene sequence analyses. FEMS Yeast Res., 3: 417-432.

Leblond J.D., Schultz T.W., Sayler G.S. (2001). Observations on the preferential biodegradation of selected components of polyaromatic hydrocarbon mixtures. Chemosphere, 42: 333343.

Lotfabad S.K.,Gray M.R. (2002). Kinetics of biodegradation of mixtures of polycyclic aromatic hydrocarbons. Appl. Microbiol. Biotechnol., 60: 361-366.

Mastrangelo G., Fadda E., Marzia V. (1996). Polycyclic aromatic hydrocarbons and cancer in man. Environ. Health Perspect., 104: 1166-1170.

McGillivray A.R., Sharis M.P. (1993). Biotransformation of polycyclic aromatic hydrocarbons by yeasts isolation from coastal sediments. Appl. Environ. Microbiol., 59: 1613-1618.

McNally D.L., Mihelcic J.R., Lueking D.R. (1999). Biodegradation of mixtures of polycyclic aromatic hydrocarbons under aerobic and nitrate-reducing conditions. Chemosphere, 38: 1313-1321.

Ooi B.G., Mulisa A., Kim H.Y., Chong N.S. (2003). Methods development for the detection of trace metabolites from the biodegradation of polycylclic aromatic hydrocarbons by yeasts. J. Tennessee Acad. Sci., 78: 65-75.

Pan F., Yang Q., Zhang Y., Zhang S., Yang M. (2004). Biodegradation of polycyclic aromatic hydrocarbons by Pichia anomala. Biotechnol. Lett., 26: 803-806.

Ren H., Zanma S., Urano N., Endo H., Mineki S., Hayashi T. (2004). Pyrene decomposing yeasts collected from sea water of Tokyo Bay. Nippon Suisan Gakkaishi, 70: 687-692.

Romero M.C., Cazau M.C., Giorgieri S., Arambarri A.M. (1998). Phenanthrene degradation by microorganisms isolated from a contaminated stream. Environ. Pollut., 101: 355-359.

Yang Q.X., Yang M., Pritsch K., Yediler A., Hagn A., Schloter M., Kettrup A. (2003). Decolorization of synthetic dyes and production of manganese-dependent peroxidase by new fungal isolates. Biotechnol. Lett., 25: 709-713.

Yuan S.Y., Wei S.H., Chang B.V. (2000). Biodegradation of polycyclic aromatic hydrocarbons by a mixed culture .Chemosphere, 41: 1463-1468.

Zinjarde S.S., Pant A.A. (2002). Hydrocarbon degraders from tropical marine environments. Mar. Pollut. Bull., 44: 188-121. 